\title{
CORRECTION
}

\section{Author Correction: QAP14 suppresses stemness and metastasis of breast cancer via the activation of dopamine D1 receptor}

Ling Yong ${ }^{1}$, Ye Yao ${ }^{1}$, Guo-shu Chen ${ }^{2}$, Xiao-xue Yan ${ }^{2}$, Yu-chen Guo ${ }^{1}$, Meng-yi Han ${ }^{1}$, Jun-sheng Xue ${ }^{1}$, Wei-zhe Jian ${ }^{1}$ and Tian-yan Zhou ${ }^{1}$ Acta Pharmacologica Sinica (2022) 43:1882-1883; https://doi.org/10.1038/s41401-022-00869-8

Correction to: Acta Pharmacologica Sinica https://doi.org/10.1038/ s41401-021-00701-9, published online 28 June 2021

The authors apologize for the mistakes in the final assembling of figures: (1) in Fig. 5d-f, the concentration of QAP14 is $4 \mu \mathrm{M}$ rather than $8 \mu \mathrm{M} ;(2)$ in Fig. 5e, representative images of MDA-MB-231 cells were misplaced inadvertently. The correct figures are presented below. The results or conclusions are not affected by this correction. The authors sincerely apologize for any inconvenience caused to the journal and readers.

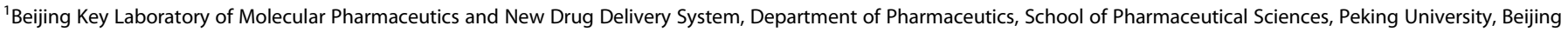
100191, China and ${ }^{2}$ Chemical Basic Laboratory, School of Chemistry and Chemical Engineering, Guangzhou University, Guangzhou 510006, China

Correspondence: Tian-yan Zhou (tianyanzhou@bjmu.edu.cn)

The original article can be found online at https://doi.org/10.1038/s41401-021-00701-9.

Published online: 26 January 2022 
a
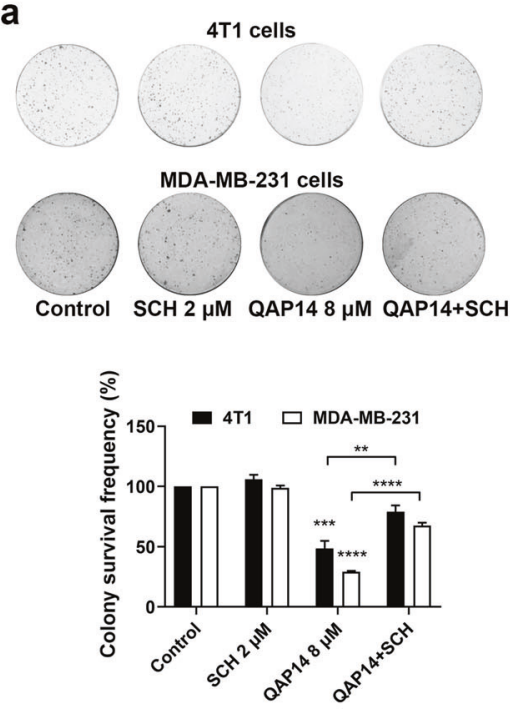

d
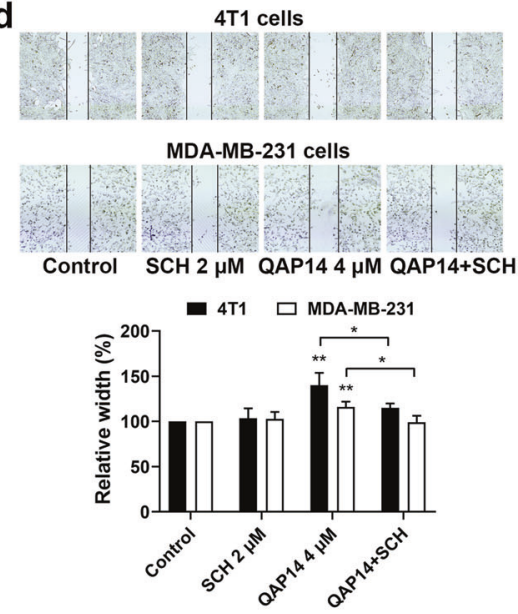

g

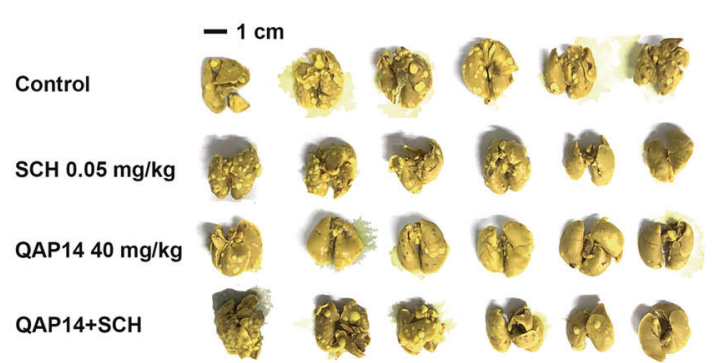

e b

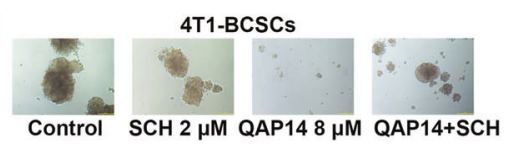

C

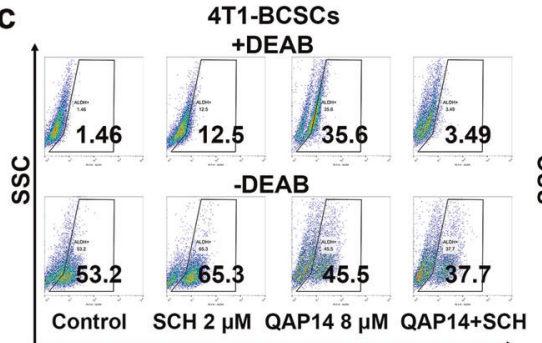

ALDH
MDA-MB-231-BCSCs

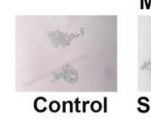

SCH $2 \mu \mathrm{M}$ QAP14 $8 \mu \mathrm{M}$ QAP14+SCH

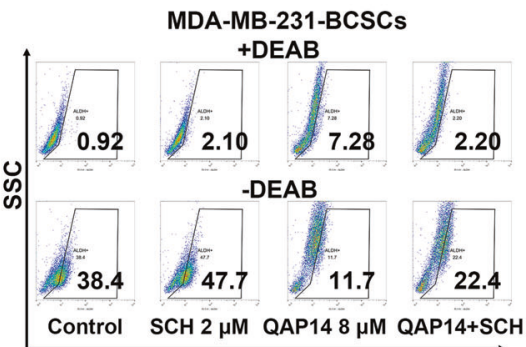

ALDH
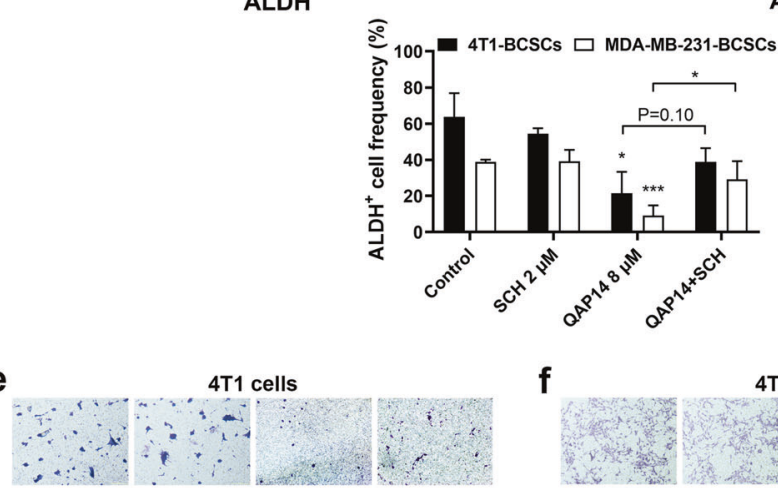

MDA-MB-231 cells
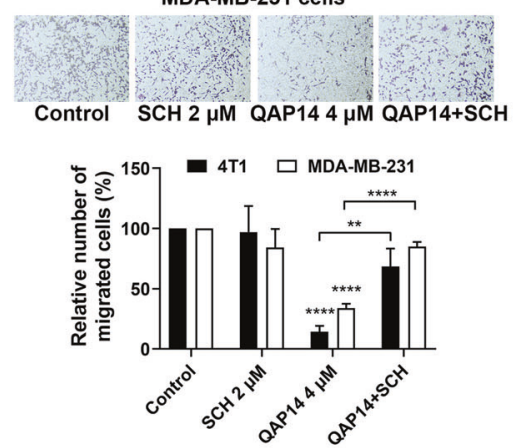

f
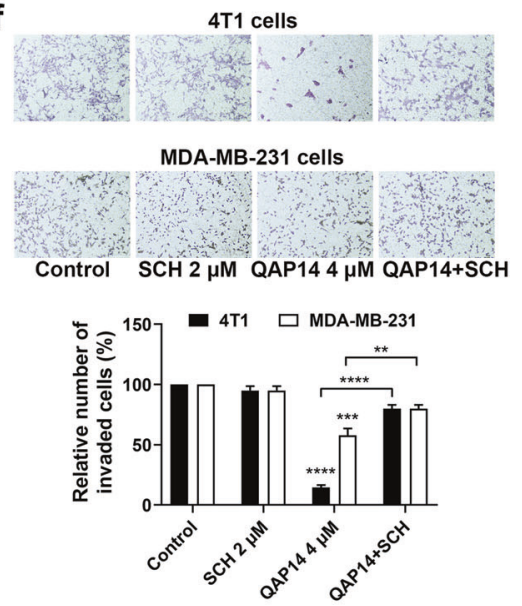

h

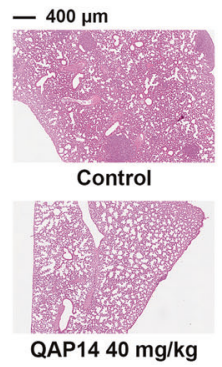

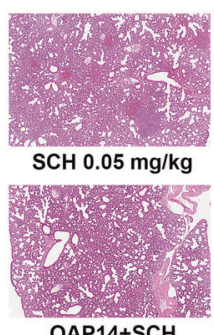

Fig. 5 D1DR antagonist SCH partially antagonized the regulatory effects of QAP14 on metastatic breast cancer. a 4T1 and MDA-MB-231 cells were treated with $8 \mu \mathrm{M}$ QAP14 alone or in combination with $2 \mu \mathrm{M} \mathrm{SCH}$ for $48 \mathrm{~h}(n=3$ per group). Colonies at the end of experiment were shown. b Mammospheres derived from 4T1 and MDA-MB-231 cells were cultured with $8 \mu \mathrm{M}$ QAP14 with or without $2 \mu \mathrm{M}$ SCH for $48 \mathrm{~h}$ ( $n=3$ per group). Representative images were shown. c The ALDH-positive cell frequency of 4T1-BCSCs and MDA-MB-231-BCSCs were detected by flow cytometry after treatment with $8 \mu \mathrm{M}$ QAP14 alone or in combination with $2 \mu \mathrm{M} \mathrm{SCH}$ for $48 \mathrm{~h}(n=3)$. d Before being treated with $4 \mu \mathrm{M}$ QAP14 and/or $2 \mu \mathrm{M} \mathrm{SCH}$ for $12 \mathrm{~h}, 4 \mathrm{~T} 1$ and MDA-MB-231 cells were scratched with pipette tips, and the wound area of each group was pictured and measured at the end of experiments $(n=3)$. e 4 T1 and MDA-MB-231 cells were exposed to $4 \mu$ M QAP14 alone or in combination with 2 $\mu \mathrm{M} \mathrm{SCH}$ for $16 \mathrm{~h}$ and the images of migrated cells were recorded $(n=3)$. $\mathbf{f}$ Transwell invasion assay was used to detect cell invasion. Cells were cultured with $4 \mu \mathrm{M}$ QAP14 with or without $2 \mu \mathrm{M} \mathrm{SCH}$ for $32 \mathrm{~h}$ (4T1 cells) and $24 \mathrm{~h}$ (MDA-MB-231 cells) $(n=3)$. g Photographs of the lungs taken out from the 4T1 tumor-bearing mice treated with QAP14 alone or in combination with SCH were shown and the number of metastatic nodules in each group was calculated $(n=6)$. The black scale bar indicates $1 \mathrm{~cm}$. $\mathbf{h}$ Representative histopathological appearance of the lungs after H\&E staining in each group was shown. The black scale bar indicates $400 \mu \mathrm{m}$. Data are presented as mean \pm SD. ${ }^{*} P<0.05,{ }^{* *} P<0.01,{ }^{* * *} P$ $<0.001$, ${ }^{* * *} P<0.0001$ compared with the corresponding control group (if not indicated). 